\title{
Scientists take share of blame for this year's poor Soviet harvest
}

\section{London}

THE lateness of the harvest this year is already causing heart-searching and rethinking among Soviet agricultural planners. One of the last major events of the Brezhnev era was the Food Programme, issued in June 1982, which was meant to ensure the long-term ability of the Soviet Union to feed its population by the year 2000. Although some lip-service is still paid to this programme, there now seems to be a tacit assumption that it will not materialize in its original form - and, indeed, one of its major features, the southward diversion of the north-flowing Siberian rivers, has been shelved.

Nevertheless, the main premise of the Food Programme persists - scientists should be more efficiently mobilized in the service of agriculture. A resolution of the All-Union Council of Ministers and Central Committee of the Communist Party of the Soviet Union in August took the same line. As part of the general "restructuring" of science on to a costefficiency basis, it offered financial incentives for research groups and institutes which contribute to increased productivity in agriculture. The profits from such innovations are, according to the new resolution, to be shared between the researchers and the farms which put the new methods into operation - thereby countering one of the main objections of scientists in past years, that workers on collective and state farms, who for some years now have enjoyed guaranteed wages, were not greatly interested in the changes and extra efforts involved in trying out new crops or procedures.

The August 1987 resolution, "on improving the scientific back-up for the country's agro-industrial complex", has a more sophisticated approach to science than previous decrees. Instead of adopting the Brezhnev approach to the "chemicization of agriculture", which advocated the use of pesticides and mineral fertilizers, it speaks of an "integrated" approach to pest control, using "ecologically safe" plant protection agents, including natural predators. Fertilizers are to be applied in accordance with growth and development, and there is to be more theoretical research into the mineral nutrition of plants. Instead of grandiose irrigation schemes the emphasis is on efficient use of existing resources, including drip-feed and synchronous pulse irrigation. Now more productive strains of livestock and plants are to be developed, including adaptations for the arid zones.

All this implies, that the scientists have been failing in their task - and Pravda said as much in a leading article on the new resolution. The resolution "defined" the All-Union Lenin Academy of Agricultural Sciences as the "supreme" centre for the "comprehensive scientific back-up programme" but, Pravda said, it has failed to assume a leading role in the necessary experimental and implementation work. The All-Union Research Institute of the Electrification of the Agricultural Economy and the All-Union Research Institute of the Physiology, Biochemistry and Nutrition of Agricultural Livestock were singled out as examples of "low resultativity". In particular, said Pravda, the new programme would necessitate increased efforts from the higher education sector, including major changes in training and updating courses and the establishment of special faculties for grading the qualifications of agricultural scientists and lecturers.

Two weeks ago a feature article in Pravda by Lenin-Prize winner G. Georgiev, which was outspoken even for the current era of glasnost, pinpoints the major legacy of Lysenkoism as an intense shortage of trained research personnel, a lack of proper appraisal of research results, and the absence of a small network of top-level Iaboratories (Georgiev spoke of 20-30) which would act as pacesetters for the rest. (What, one is left wondering, became of the massive emergency investment in molecular biology and genetics authorized in May 1974 which was intended to supply just such a base?)

Other scientists maintain that they have been working for agriculture on the lines now proposed for years, but that their results have been ignored or misapplied. In a recent Soviet television documentary, the president of the Moldavian Academy of Sciences, Dr Aleksandr Zhuchenko, spoke of major top-level errors in landuse, caused by politicians overriding the scientists' recommendations. In one case, he said, the All-Union Ministry of Land Reclamation and Water Resources had authorized plans for an irrigation system in the face of protests from scientists who pointed out that the water in question was unsuitable and would damage Moldavia's black soils. Zhuchenko further questioned the official Soviet approach to farm production targets. Instead of aiming at high yields in favourable years - and then writing off subsequent low results as due to adverse weather - the agricultural planners should aim at a balanced programme, producing good yields every year, including dry years, and should eschew doubtful management practices that can produce a one-off record crop, but from which the soil will then take ten years to recover.

\section{Fish psychology is big business}

Tokyo

JAPANESE fisheries scientists are resorting to psychology to keep fish under their control. An experimental station in the southern island of Kyushu is applying electric-shock treatment to keep fish within a netless farm, while another is using the Pavlov technique and sound to confine red sea bream in an open bay.

Fish farming is big business in Japan with an annual production of just over one million tons - enough to satisfy the fish consumption of France. The electric fish farm is only in the very early stages of development. Hitachi Zosen Corporation, a shipbuilding company, and Kumamoto Prefectural fisheries station are testing the system in a tank. The farm is defined by three rings of metal stakes; the central ring is electrified. The distance between the central and outer ring is short, creating a strong electric field. Fish confined within the inner ring encounter an electric field that increases in strength outwards if they stray beyond that ring. Finally they are stunned before they can escape. When the fish regain consciousness on the sea floor they usually swim back to the inner circle. The electric farm avoids the problem of clogged nets which causes reduced oxygen supply and disease.

The sonic fish farm at Oita Prefectural fisheries station in Kyushu is at a much more advanced stage and employs quite the opposite psychological approach. Red sea bream are raised from eggs in tanks and then netted enclosures in the sea to the $3-\mathrm{cm}$ stage. They are then conditioned to associate sound with food. Sounds are played to them at the time of feeding. At first a piano piece composed by an Oita University professor was used, but the fish did not like the variation in frequency. Bongo drums were not to their liking either. In the end, a plain 'pooh pooh' at 300 hertz and 50 decibels did the trick.

After 80 days of sound conditioning, the fish, now $10 \mathrm{~cm}$ long, are released into the bay where all the latest high-tech equipment is brought to bear to prevent the sea bream from swimming away.

One of the great advantages of the ranch is that the costs of feed and manpower are greatly reduced -70 per cent of production costs of conventional fish farms is taken up by food and labour. And even although the 20 per cent recovery for released fish is less than that of a conventional farm (80-90 per cent), Yasumura estimates that production costs per $\mathrm{kg}$ for a sonic fish farm will be less. And as the fish look and taste like their natural wild cousins, he expects them to command twice the price of the conventional farm variety.
David Swinbanks 